\title{
Simulation-based evaluation of zeolite adsorbents for the removal of emerging contaminants
}

\author{
Michael Fischer ${ }^{1,2}$ \\ 1) Crystallography Group, Department of Geosciences, University of Bremen, Klagenfurter Straße 2-4,
} D-28359 Bremen, Germany

2) MAPEX Center for Materials and Processes, University of Bremen,

D-28359 Bremen, Germany

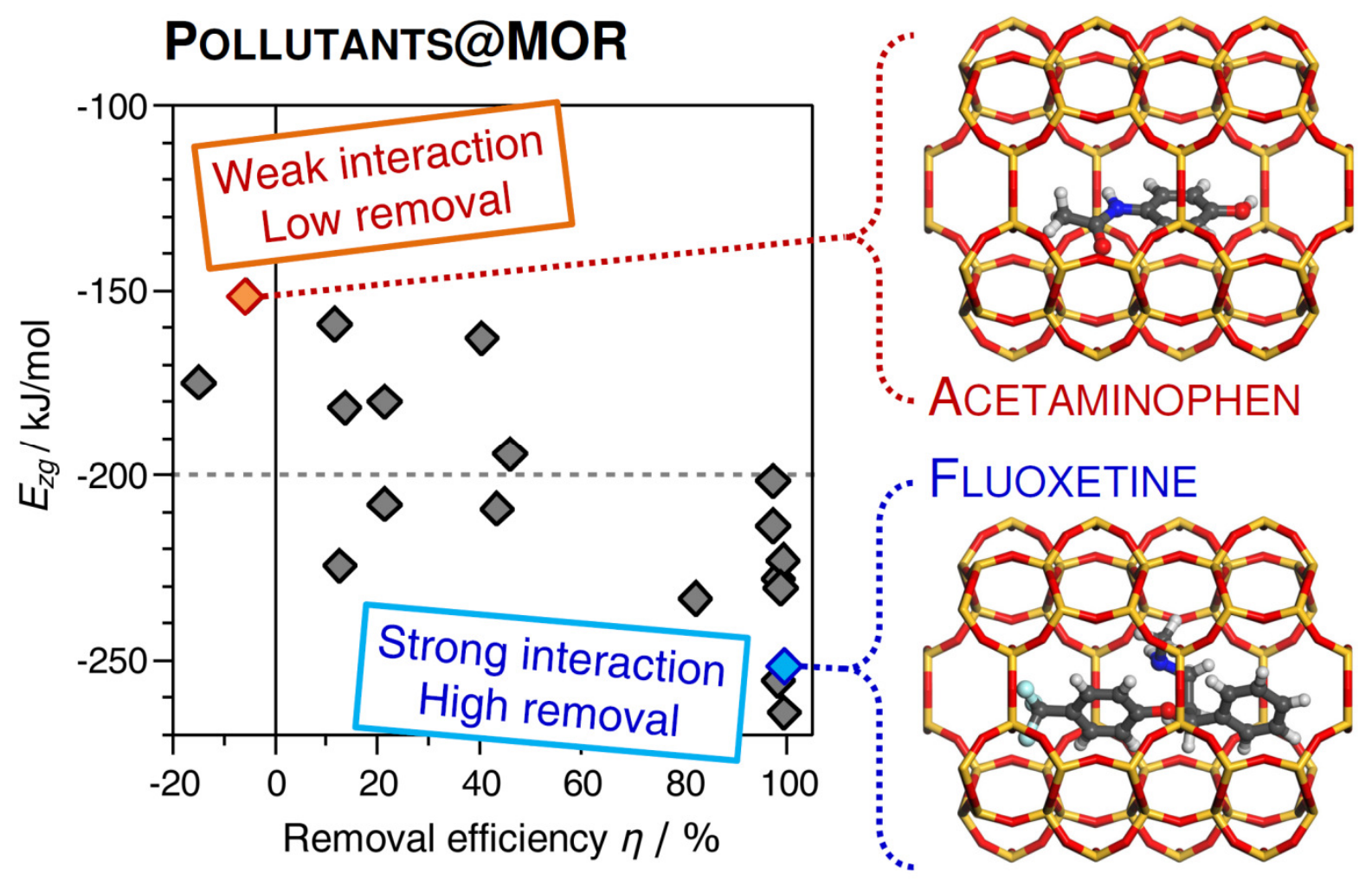




\begin{abstract}
A number of experimental studies have evaluated the potential of hydrophobic high-silica zeolites for the adsorptive removal of emerging organic contaminants, such as pharmaceuticals and personal care products, from water. Despite the widespread use of molecular modelling techniques in various other fields of zeolite science, the adsorption of pharmaceuticals and related pollutants has hardly been studied computationally. In this work, inexpensive molecular simulations using a literature force field (DREIDING) were performed to study the interaction of 21 emerging contaminants with two all-silica zeolites, mordenite (MOR topology) and zeolite $Y$ (FAU topology). The selection of adsorbents and adsorbates was based on a previous experimental investigation of organic contaminant removal using high-silica zeolites (Rossner et al., Water Res. 2009, 43, 3787-3796). An analysis of the lowest-energy configurations revealed a good correspondence between calculated interaction energies and experimentally measured removal efficiencies (strong interaction - high removal), despite a number of inherent simplifications. This indicates that such simulations could be used as a screening tool to identify promising zeolites for adsorption-based pollutant removal prior to experimental investigations. To illustrate the predictive capabilities of the method, additional calculations were performed for acetaminophen adsorption in 11 other zeolite frameworks, as neither mordenite nor zeolite $Y$ remove this pharmaceutical efficiently. Furthermore, the lowestenergy configurations were analysed for selected adsorbent-adsorbate combinations in order to explain the observed differences in affinity.
\end{abstract}




\section{Introduction}

Due to the ever-increasing use of pharmaceuticals and personal care products in modern society, these organic pollutants are ubiquitously present in urban wastewaters.[1-3] Incomplete removal of these "emerging contaminants" by conventional wastewater treatment facilities leads to their discharge into the aquatic environment, giving rise to significant concerns with regard to environmental and health issues.[4-9] Agricultural runoff constitutes an additional source of pollution, as pharmaceuticals are widely used in livestock farming.[10] Analyses of water samples from all continents (including Antarctica[11]) have shown that environmental pollution through pharmaceuticals is a problem of a truly global scale: A 2016 survey compiling measured environmental concentrations from more than 1,000 publications showed that $>600$ different pharmaceutical substances (including transformation products) have been detected in the environment, with individual datasets coming from 71 countries across the world.[1] To mitigate potentially harmful consequences, such as the development of antibiotic resistance in aquatic reservoirs,[12] it is necessary to design improved wastewater treatment technologies that are able to efficiently remove pharmaceuticals and related organic pollutants. Currently, oxidation and advanced oxidation processes, membrane filtration, and adsorption-based processes are seen as the most promising advanced treatment options, with each technology having advantages and drawbacks.[7, 9, 13-17]

In the field of adsorption-based removal of emerging contaminants, activated carbons (ACS) and related carbon-based materials constitute the most widely studied class of adsorbents,[13, 16-19] but several groups of silica-based materials have also been proposed,[17, 20] among them clay minerals,[16, 21-23] mesoporous silicas,[24, 25] natural zeolites,[21, 26, 27] and synthetic hydrophobic high-silica zeolites.[28] The first systematic study of highly siliceous zeolites targeting this application was reported in 2009 by Rossner et al., who investigated mordenite (MOR topology [29]) and zeolite $Y$ (FAU topology) for the adsorption of 25 organic contaminants from spiked lake water.[30] They observed quantitative removal of several compounds by mordenite, whereas zeolite $Y$ removed only one pharmaceutical, the antidepressant fluoxetine, to a significant extent. In that work, an AC adsorbent outperformed both zeolites. Despite this, there are some practical aspects that might favour zeolites over activated carbons, at least for some applications: As zeolites possess well-defined micropores with diameters in the range of 5 to $10 \AA$, there is only negligible coadsorption of natural organic matter (NOM), which cannot enter these narrow pores.[31] Pore blockage by NOM can constitute a significant problem for ACs, which have a broader pore size distribution.[19] The higher thermal stability of zeolites is a second advantage, as it permits thermal regeneration and reuse of the adsorbent, whereas ACs may partially decompose during thermal treatment.[13] For these reasons, a number of experimental studies have followed up the work of Rossner et al. in evaluating the performance of high-silica zeolites for the removal of pharmaceuticals and related pollutants:[31, 32, 41, 42, 33-40] For example, De Ridder et al. studied the adsorption of 15 pharmaceuticals of varying hydrophobicity and size, as well as seven nitrosamines, in high-silica mordenite and ZSM-5 (MFI topology).[31] They observed efficient removal of positively charged, neutral, and negatively charged pharmaceuticals by the MOR-type adsorbent, whereas ZSM- 5 rejected negatively charged species. This difference was explained with the lower negative surface charge of the MOR system, which had a higher Si/Al ratio (Si/Al = 100 compared to 40 for $\mathrm{MFI}$ ). A series of studies employing high-silica zeolites for pharmaceutical adsorption was reported by Braschi, Martucci, and co-workers.[32, 33, 35-38, 40-42] These authors investigated 
pharmaceuticals from different groups, among them antibiotics (e.g., sulfonamides, erythromycin), the anticonvulsant carbamazepine, and the analgesic ketoprofen, and also considered different adsorbents (zeolite $\mathrm{Y}$, mordenite, ZSM-5, zeolite beta). In several of their works, they performed Xray diffraction experiments on pharmaceutical-loaded zeolite samples to locate the adsorbate in the zeolite pores, and to evaluate distortions of the framework upon adsorption.[32, 35, 36, 40] Moreover, they employed vibrational and NMR spectroscopy to study the role of host-guest and guest-guest interactions, e.g., to investigate the role of hydrogen bonds and the extent of dimer formation in the zeolite pores. $[33,37]$ While these experimental investigations were complemented by first-principles calculations in the framework of density functional theory (DFT), there are few other computational investigations dealing with pharmaceutical adsorption in zeolites. In the view of the widespread use of computational chemistry methods in zeolite science,[43, 44] this appears somewhat surprising. In the field of molecular mechanics calculations, force-field based Monte Carlo (MC) and molecular dynamics (MD) simulations have been employed to study the adsorption and/or diffusion of organic molecules in all-silica zeolites for several species of considerable complexity, including substituted aromatics,[45-50] organic structure-directing agents (OSDAs),[51-57] and glucose.[58] In contrast to this, applications of force field methods to study the interaction of pharmaceuticals with zeolites are scarce, with the MD investigation of salbutamol and theophylline diffusion in zeolite beta by Fatouros et al. being a rare example.[59] These authors observed that the rigid theophylline molecule is unable to diffuse through the channels of zeolite beta, whereas the more flexible salbutamol can move along the channels, despite the similar molecular dimensions. Experimentally, it could be confirmed that salbutamol is indeed adsorbed inside the pores, whereas theophylline mostly remains at the external surface of the zeolite particles, affecting the release properties, which are important for drug delivery applications. The work of Fatouros et al. thus demonstrated the usefulness of computational methods to "screen" combinations of zeolite adsorbents and drug molecules prior to experimental investigations. Given their extensive use in other fields, mentioned above, it is somewhat surprising that similar modelling strategies have not been employed more frequently to study the adsorption of pharmaceuticals in zeolites, aiming at applications in either drug delivery or wastewater treatment.

The present work aims to establish whether a fairly "generic" molecular simulation approach can be used for an approximate prediction of the removal efficiency of zeolite adsorbents for organic pollutants. Force-field based simulations are performed to find low-energy configurations of 21 organic molecules in zeolites MOR and FAU. The selection of pollutants follows the experimental work of Rossner et al.[30] This experimental study constitutes a particularly suitable reference for the following reasons:

- It covers a large set of $>20$ pollutants, whereas most other experimental works have focussed on one or a few guest molecules.

- Six of the pharmaceuticals included in that study have been classified as high priority pharmaceuticals of particular relevance to the water cycle in a 2009 survey (carbamazepine, diclofenac, gemfibrozil, ibuprofen, naproxen, sulfamethoxazole).[60]

- Low concentrations in the $\mathrm{ng} / \mathrm{L}$ range were studied, meaning that guest-guest interactions should be negligible.

- The adsorbents used have very high Si/Al ratios, and can thus be reasonably approximated using all-silica models. 
The large majority of the 21 pollutants considered in the present work are used in medicine, but some organic compounds that find other uses are also included (e.g., the herbicide atrazine and the flame retardant TCEP). An analysis of the computational results shows that low calculated host-guest interaction energies (corresponding to strong interaction) coincide with high experimental removal efficiencies, with only few exceptions. For three pollutants, an analysis of low-energy configurations is used to understand the differences in affinity among different adsorbent-adsorbate pairs. Finally, the approach is extended to the study of acetaminophen (paracetamol) adsorption in 11 other zeolite frameworks, as neither MOR nor FAU appear well suited to remove this species.

It should be noted that the computationally inexpensive approach employed in the present work makes use of a number of inherent simplifications, which are discussed in detail in the Discussion section. As a consequence, it has to be emphasised that this approach does not strive to achieve a highly accurate atomic-level picture of the interaction between zeolites and complex organic pollutants. Instead, a simple approach like the one proposed here could be used to identify those adsorbent-adsorbate combinations that are most interesting for experimental investigations or for more detailed computational studies, e.g., by means of electronic structure methods.

\section{Computational details}

\section{Models of zeolite adsorbents}

The models of all-silica zeolites with MOR and FAU topology were taken from the IZA database.[29] Due to the very low amount of framework aluminium of the zeolite adsorbents used in the experimental study by Rossner et al. (MOR: Si/Al = 115; FAU: Si/Al = 405),[30] it appears reasonable to approximate them as purely siliceous zeolites. In addition, the adsorption of acetaminophen was studied in 11 other zeolite frameworks, all of which are available in all-silica or high-silica form. Framework type codes (FTCs)[29] and materials names of corresponding high-silica/all-silica zeolites are compiled in Table 1.

Prior to the MC simulations, the zeolite structures were optimised using GULP,[61] employing the interatomic potential parameters devised by Sanders, Leslie, and Catlow (SLC).[62] The SLC parameters have been found to give excellent agreement with experimental lattice parameters for all-silica zeolites.[63, 64] In all calculations described in the following subsection, supercells were used for those zeolites where the conventional unit cell is small enough to cause a potentially significant interaction of an adsorbed molecule with its image in the next unit cell. While the unit cell of FAU is so large that no cell multiplication was needed, the unit cell of MOR was tripled along the $c$ axis $(1 \times 1 \times 3)$. Supercells used for all frameworks considered are listed in Table 1 , and SLC-optimised structures in the respective supercells are supplied as Supporting Information (in CIF format). 
Table 1: Framework type codes of zeolite frameworks considered, material name(s) of high-silica or all-silica zeolites,[65] and dimensions of supercells used in the simulations.

\begin{tabular}{lcc}
\hline \hline FTC & Material name(s) & $\begin{array}{c}\text { Supercell } \\
(\boldsymbol{a} \times \mathbf{b} \times \boldsymbol{c})\end{array}$ \\
\hline MOR & Mordenite & $1 \times 1 \times 3$ \\
FAU & Dealuminated Y & $1 \times 1 \times 1$ \\
\hline AFI & SSZ-24 & $2 \times 2 \times 3$ \\
BEA & Zeolite beta & $2 \times 2 \times 1$ \\
EUO & EU-1 / ZSM-50 & $2 \times 1 \times 1$ \\
FER & Ferrierite & $2 \times 3 \times 1$ \\
MEI & ZSM-18 & $2 \times 2 \times 2$ \\
MEL & ZSM-11 / Silicalite-2 & $1 \times 1 \times 2$ \\
MFI & ZSM-5 / Silicalite-1 & $1 \times 1 \times 2$ \\
MTT & ZSM-23 & $4 \times 1 \times 2$ \\
MTW & ZSM-12 & $1 \times 4 \times 2$ \\
MWW & MCM-22 / ITQ-1 & $2 \times 2 \times 1$ \\
TON & ZSM-22 / Theta-1 & $2 \times 2 \times 4$ \\
\hline \hline
\end{tabular}

\section{Models of organic pollutants}

The molecular structures of 21 organic pollutants included in the experimental study by Rossner et al. were obtained from openly available data repositories, primarily the PubChem[66] and CheBi[67] databases. The molecules were then loaded into the DS Biovia Materials Studio 2019 (MS) software.[68] After addition of hydrogen atoms (if required), an initial structure optimisation using the DREIDING force field[69] was carried out (MS Forcite module). As an energy minimisation will only deliver a local minimum, it was followed by an MS Forcite Anneal job, also using the DREIDING force field. Such an annealing corresponds to a molecular dynamics run that periodically increases and decreases the simulation temperature, thereby allowing for the sampling of different local minima. Each Anneal job consisted of 25 cycles with a maximum temperature of $3000 \mathrm{~K}$ and a minimum temperature of $300 \mathrm{~K}$, using 100,000 steps per cycle (step size $1 \mathrm{fs}$ ) in the NVE ensemble. The structures obtained at the end of each of the 25 cycles were optimised, and the structure with the lowest energy was then taken as input for the MC simulations, described in the following section. The DREIDING-optimised molecular structures are supplied as Supporting Information (as MDL molfiles).

\section{Monte Carlo simulations}

Configurational-bias MC simulations for a loading of one organic molecule per simulation box (unit cell or supercell, as given in Table 1) were performed in order to obtain a set of low-energy configurations. These simulations were carried out in the NVT ensemble for a temperature of $298 \mathrm{~K}$. At the beginning of each simulation, up to $10,000,000$ trial insertion steps were used to place the molecule in the zeolite pores (this procedure failed in some cases for MOR, discussed below). This 
was followed by an equilibration stage of $2,000,000 \mathrm{MC}$ steps and a production stage of $3,000,000$ steps from which the configurations were extracted. The probability of different types of MC steps was set to 2:1:1:1 for regrowth:rotation:translation:torsion twisting, and the amplitudes of rotation, translation, and torsion twisting were rescaled during the $\mathrm{MC}$ run to give an acceptance probability of approximately 0.5 . Prior to the $\mathrm{MC}$ simulations, torsional degrees of freedom were defined by specifying the relevant torsion angles in Materials Studio.

Only van der Waals (vdW) interactions between organic pollutants and the pore walls were considered in these calculations. These interactions were modelled using pairwise Lennard-Jones (LJ) potentials, employing Lorentz-Berthelot mixing rules, a cutoff distance of $10 \AA$, and atomic $\mathrm{L}$ parameters taken from the DREIDING force field.[69] While the zeolite frameworks were treated as rigid, the torsion angles of the adsorbed organics change during the configurational-bias $\mathrm{MC}$ simulations. As a consequence, the intramolecular contribution to the total energy varies during the simulation, and this contribution was also calculated using DREIDING parameters for bond stretching, angle bending, torsions, etc. Although the DREIDING force field, being a "generic" multipurpose force field, cannot be expected to be particularly accurate for the adsorption of organic pollutants in zeolites, it has been previously used with considerable success in computational studies of OSDAs interacting with zeolite frameworks.[51-54, 57] As DREIDING-based calculations were found to be able to predict promising OSDAs for zeolite synthesis, it can be expected that this force field should also be suited to represent the interaction between zeolites and other, comparably complex organic molecules reasonably well.

At least three independent MC simulations were performed for each combination of adsorbent and adsorbate. From each simulation, the 20 configurations with the lowest total energies were extracted and re-optimised (MS Forcite, DREIDING force field), keeping the zeolite framework rigid. The zeolite-guest interaction energy $E_{\mathrm{zg}}$ was then calculated by subtracting the total energy of the isolated pollutant molecule $E_{\text {guest }}$ from the total energy of the zeolite-guest system $E_{\text {zeo+guest }}$ (because the zeolite framework is treated as rigid, its internal energy is zero): $E_{z \mathrm{~g}}=E_{\text {zeo+guest }}-E_{\text {guest }}$. The value of $E_{\mathrm{zg}}$ obtained for the configuration with the lowest energy was used in the analysis presented below.

In a few instances, the insertion of the guest molecules into the MOR structure using MC simulations failed. This was the case for carbamazepine, diazepam, dilantin, hydrocodone, and pentoxifylline. For these species, the pollutant molecule was inserted manually, and MS Forcite Anneal jobs analogous to those described above were run, starting from different initial configurations (again using a rigid zeolite framework). After a re-optimisation of the structures obtained at the end of each annealing cycle, the system with the lowest energy was selected. Regardless of the sampling procedure (MC or MD annealing), low-energy configurations obtained from independent runs were usually close in energy, giving confidence that a sufficiently large number of configurations had been sampled. 


\section{Results}

\section{Adsorption of pollutants in MOR}

In their experimental work, Rossner et al. reported the concentrations of 25 pollutants in adsorbentfree blank samples, and in water samples equilibrated with $100 \mathrm{mg} / \mathrm{L}$ of MOR- and FAU-type adsorbents (HSZ-690HOA and HSZ-390HUA, both obtained from the commercial supplier Tosoh USA).[30] On the basis of their data, the removal efficiency $\eta$ of a zeolite adsorbent for a given pollutant can be calculated as $\eta=100 *\left(C_{\text {blank }}-C_{\text {zeo }}\right) / C_{\text {blank }}$, where $C_{\text {blank }}$ is the concentration in the blank sample and $C_{\text {zeo }}$ is the concentration in the sample mixed with zeolite. Mordenite removes more than $90 \%$ of 11 pollutants, and between 40 and $90 \%$ of four others (atrazine, carbamazepine, naproxen, trimethoprim). It is worth noting that negative values of $\eta$ are found for acetaminophen and diclofenac. Such negative removal rates are not particularly uncommon, and they have been observed in various studies of real wastewaters. $[4,6]$ While the actual origins are unknown for this particular study, negative removal rates are typically attributed to chemical transformations or sampling/measurement issues.

Out of the 25 pollutants studied by Rossner et al., the present work investigated 21 , omitting the following substances:

- Of the four hormones estradiol, estriol, estrone, and ethynylestradiol, only estrone was considered, as the similar molecular structures should lead to very similar adsorption behaviour (experimentally, all four of them were fully removed by MOR, but not by FAU).

- The iodine-containing contrast agent iopromide was not considered, because the DREIDING parameters for iodine have been validated much less stringently than those for lighter elements.[69]

The $E_{\mathrm{zg}}$ values obtained for the most favourable configurations of the remaining 21 molecules are compiled in table 2 , together with the experimentally measured removal efficiencies.

Experimentally, MOR removes 8 of the 21 molecules quantitatively (DEET, estrone, fluoxetine, gemfibrozil, ibuprofen, meprobamate, oxybenzone, triclosan). The computed $E_{\mathrm{zg}}$ values for these molecules range from $-202 \mathrm{~kJ} / \mathrm{mol}$ to $-264 \mathrm{~kJ} / \mathrm{mol}$. A similarly strong interaction is predicted for naproxen and atrazine, which are removed with efficiencies of $\sim 80 \%$ and $\sim 40 \%$, respectively. Concerning the other two species that are removed with efficiencies of 40 to $50 \%$, an intermediate interaction strength is obtained for trimethoprim $(-194 \mathrm{~kJ} / \mathrm{mol})$, whereas the interaction with carbamazepine is rather weak $(-163 \mathrm{~kJ} / \mathrm{mol})$. Among the remaining 9 pollutants, which are not removed to any appreciable extent, $E_{\mathrm{zg}}$ values close to zero are calculated for diazepam and hydrocodone. It can be concluded that these molecules do not fit into the channels of MOR, incurring a large energetic penalty if they are "forced" into the channels in the simulations (this also explains why the insertion of these molecules into the pores using an $M C$ approach failed). For acetaminophen, caffeine, diclofenac, dilantin, and pentoxifylline, the $E_{z \mathrm{~g}}$ values vary from -152 to $-193 \mathrm{~kJ} / \mathrm{mol}$, thus being distinctly less negative than those of the group of 8 molecules that are efficiently removed. Altogether, a relationship between the experimentally measured removal efficiency and the computed interaction strength can be identified, which is visualised in Figure 1. The only two clear exceptions from the overall trend are sulfamethoxazole and TCEP, where $E_{\mathrm{zg}}$ values of -225 and $-208 \mathrm{~kJ} / \mathrm{mol}$, respectively, are contrasted with low removal efficiencies of 13 and 
21\%. There are various possible origins for this discrepancy, such as diffusional limitations or problems in the representation of the sulfonamide and phosphate ester groups with DREIDING parameters. However, the elucidation of this aspect goes beyond the scope of the present study.

With few exceptions, it is possible to identify adsorbent-adsorbate combinations that result in an efficient removal on the basis of the $E_{\mathrm{zg}}$ values: If $E_{\mathrm{zg}}<-200 \mathrm{~kJ} / \mathrm{mol}$, a high removal efficiency can be expected. While there are a few false positive predictions, most prominently for sulfamethoxazole and TCEP, it is worth noting that there are no false negatives, in other words, no situations where a weak interaction is predicted for a case where the experimentally observed removal is essentially quantitative (carbamazepine is a borderline case that will be revisited in the Discussion). This indicates that the simulations could be used as a predictive tool to identify promising zeolite frameworks for the selective adsorption of pollutants.

Table 2: List of pollutants included in this study. For each pollutant, experimentally measured removal efficiencies $\eta$ of zeolites MOR and FAU from ref. [30] as well as calculated zeolite-guest interaction energies obtained in the present work are given. Near-quantitative removal efficiencies are highlighted in bold, and $E_{\mathrm{zg}}$ values below $-200 \mathrm{~kJ} / \mathrm{mol}$ are highlighted in italics.

\begin{tabular}{|c|c|c|c|c|c|c|c|}
\hline & & & & MOR & & FAU & \\
\hline & Use & $\begin{array}{l}\text { Sum } \\
\text { formula }\end{array}$ & $\begin{array}{c}\boldsymbol{m}_{\text {molar }} \\
{[\mathrm{g} / \mathrm{mol}]}\end{array}$ & $\begin{array}{c}\eta \\
{[\%]}\end{array}$ & $\begin{array}{c}E_{\mathrm{zg}} \\
{[\mathrm{kJ} / \mathrm{mol}]}\end{array}$ & $\begin{array}{c}\eta \\
{[\%]}\end{array}$ & $\begin{array}{c}E_{\mathrm{zg}} \\
{[\mathrm{kJ} / \mathrm{mol}]}\end{array}$ \\
\hline Acetaminophen & Analgesic & $\mathrm{C}_{8} \mathrm{H}_{9} \mathrm{NO}_{2}$ & 151.17 & -6 & -152 & -12 & -113 \\
\hline Atrazine & Herbicide & $\mathrm{C}_{8} \mathrm{H}_{14} \mathrm{ClN}_{5}$ & 215.69 & 43 & -209 & 2 & -151 \\
\hline Caffeine & Stimulant & $\mathrm{C}_{8} \mathrm{H}_{10} \mathrm{~N}_{4} \mathrm{O}_{2}$ & 194.19 & 12 & -159 & 5 & -127 \\
\hline Carbamazepine & Anticonvulsant & $\mathrm{C}_{15} \mathrm{H}_{12} \mathrm{~N}_{2} \mathrm{O}$ & 236.27 & 40 & -163 & 11 & -155 \\
\hline $\mathrm{DEET}^{1}$ & Insect repellent & $\mathrm{C}_{12} \mathrm{H}_{17} \mathrm{NO}$ & 191.27 & 97 & -202 & 6 & -147 \\
\hline Diazepam & Tranquiliser & $\mathrm{C}_{16} \mathrm{H}_{13} \mathrm{ClN}_{2} \mathrm{O}$ & 284.75 & 17 & -11 & 5 & -171 \\
\hline Diclofenac & Analgesic & $\mathrm{C}_{14} \mathrm{H}_{11} \mathrm{Cl}_{2} \mathrm{NO}_{2}$ & 296.15 & -15 & -175 & -2 & -178 \\
\hline Dilantin & Anticonvulsant & $\mathrm{C}_{15} \mathrm{H}_{12} \mathrm{~N}_{2} \mathrm{O}_{2}$ & 252.27 & 14 & -182 & 1 & -185 \\
\hline Estrone & Steroid & $\mathrm{C}_{18} \mathrm{H}_{22} \mathrm{O}_{2}$ & 270.37 & 100 & -264 & 35 & -188 \\
\hline Fluoxetine & Antidepressant & $\mathrm{C}_{17} \mathrm{H}_{18} \mathrm{~F}_{3} \mathrm{NO}$ & 309.33 & 100 & -251 & 98 & -215 \\
\hline Gemfibrozil & Anti-cholesterol & $\mathrm{C}_{15} \mathrm{H}_{22} \mathrm{O}_{3}$ & 250.34 & 98 & -256 & 6 & -178 \\
\hline Hydrocodone & Analgesic & $\mathrm{C}_{18} \mathrm{H}_{21} \mathrm{NO}_{3}$ & 299.37 & 23 & 6 & 26 & -196 \\
\hline Ibuprofen & Analgesic & $\mathrm{C}_{13} \mathrm{H}_{18} \mathrm{O}_{2}$ & 206.29 & 98 & -228 & 6 & -156 \\
\hline Meprobamate & Tranquiliser & $\mathrm{C}_{9} \mathrm{H}_{18} \mathrm{~N}_{2} \mathrm{O}_{4}$ & 218.25 & 97 & -214 & 7 & -152 \\
\hline Naproxen & Analgesic & $\mathrm{C}_{14} \mathrm{H}_{14} \mathrm{O}_{3}$ & 230.26 & 82 & -233 & 2 & -170 \\
\hline Oxybenzone & UV absorber & $\mathrm{C}_{14} \mathrm{H}_{12} \mathrm{O}_{3}$ & 228.25 & 99 & -223 & 47 & -172 \\
\hline Pentoxifylline & $\begin{array}{l}\text { Blood viscosity } \\
\text { control }\end{array}$ & $\mathrm{C}_{13} \mathrm{H}_{18} \mathrm{~N}_{4} \mathrm{O}_{3}$ & 278.31 & 21 & -180 & 3 & -190 \\
\hline Sulfamethoxazole & Antibiotic & $\mathrm{C}_{10} \mathrm{H}_{11} \mathrm{~N}_{3} \mathrm{O}_{3} \mathrm{~S}$ & 253.28 & 13 & -225 & 0 & -172 \\
\hline TCEP $^{2}$ & Flame retardant & $\mathrm{C}_{6} \mathrm{H}_{12} \mathrm{Cl}_{3} \mathrm{O}_{4} \mathrm{P}$ & 285.49 & 21 & -208 & 7 & -168 \\
\hline Triclosan & Bactericide & $\mathrm{C}_{12} \mathrm{H}_{7} \mathrm{Cl}_{3} \mathrm{O}_{2}$ & 289.55 & 99 & -230 & 45 & -168 \\
\hline Trimethoprim & Antibiotic & $\mathrm{C}_{14} \mathrm{H}_{14} \mathrm{O}_{3}$ & 290.32 & 46 & -194 & 5 & -182 \\
\hline
\end{tabular}

1) DEET = N,N-Diethyl-meta-toluamide

2) TCEP = Tri(2-chloroethyl)phosphate 


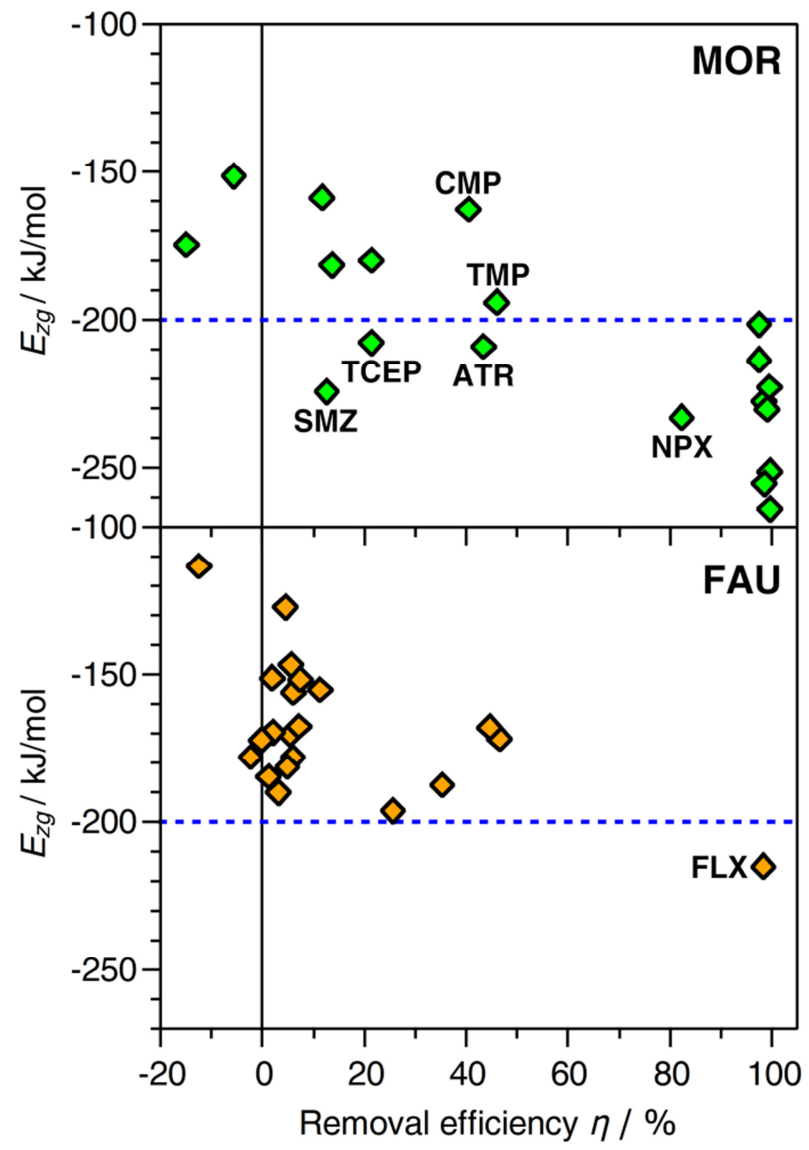

Figure 1: Plot of calculated interaction energies $E_{\mathrm{zg}}$ against experimentally measured removal efficiencies.[30] FLX = fluoxetine, NPX = naproxen, ATR = atrazine, $\mathrm{SMZ}=$ sulfamethoxazole, $\mathrm{TMP}=$ trimethoprim, CMP = carbamazepine. Data points for diazepam and hydrocodone in MOR are not shown.

\section{Adsorption of pollutants in FAU}

Experimentally, FAU-type zeolite $Y$ performs significantly worse than MOR, removing only fluoxetine essentially quantitatively, and more than $25 \%$ of four other contaminants (estrone, hydrocodone, oxybenzone, triclosan). The results for this system are included in Table 2 and Figure 1. The overall picture is considerably simpler than for MOR: Only fluoxetine is removed quantitatively, and the $E_{\mathrm{zg}}$ value of $-215 \mathrm{~kJ} / \mathrm{mol}$ is by far the lowest obtained for this zeolite, in line with the correspondence between low $E_{\mathrm{zg}}$ values and high removal efficiencies found above for MOR. This trend is not so evident for the three species that are partially removed (estrone, oxybenzone, triclosan), as the interaction energies fall essentially in the same range as those computed for molecules that are not adsorbed to any appreciable extent. This might indicate that guest-guest interactions or other specific interactions play a significant role in determining the overall affinity of FAU towards these pollutants. Altogether, the simulations clearly identify MOR as the more promising adsorbent for the removal of several of the 21 emerging contaminants, and one would certainly prioritise MOR for more detailed investigations if no previous experimental data were available. 


\section{Analysis of low-energy configurations}

In order to investigate the origins of the differences in affinity observed above, the lowest-energy configurations of fluoxetine, ibuprofen, and acetaminophen in MOR and FAU were analysed (Figures 2, 4, and 5). These three species were selected due to their qualitatively different behaviour: Fluoxetine is strongly adsorbed by both MOR and FAU, ibuprofen interacts strongly with MOR, but not with FAU, and acetaminophen interacts rather weakly with both zeolites. Prior to discussing the configurations of the adsorbed molecules, it is useful to summarise the key features of the zeolites' pore topology: MOR possesses channels bordered by 12-membered rings (12MR) running along the c-direction, which are connected by eight-membered rings (8MR).[29] Because the 8MR channels are only accessible to very small molecules, not to the bulky organics considered in the present work, the pore system can be considered as being one-dimensional, and the eight-membered rings correspond to side pockets of the larger channels. In FAU, large, nearly spherical "supercages" are connected by $12 \mathrm{MR}$ windows along the cubic $<111>$ directions, forming a 3D pore system.

As shown in Figure 2, the fluoxetine molecule in MOR is oriented along the 12MR channel. Interestingly, the conformation of the adsorbed molecule is very different to the isolated state, with both phenyl rings lying almost in one plane, and a folded-up $\mathrm{N}$-methyl-ethanamine chain. The molecule is oriented in a way that the phenyl rings point towards the $8 \mathrm{MR}$ side pockets. In contrast, the conformation of fluoxetine adsorbed in FAU is very to the free molecule. The central part of the molecule occupies a 12-ring window connecting two supercages, and both phenyl moieties and the $\mathrm{N}$-methyl-ethanamine side chain are located above assemblies of 4- and 6-rings bordering these cages.
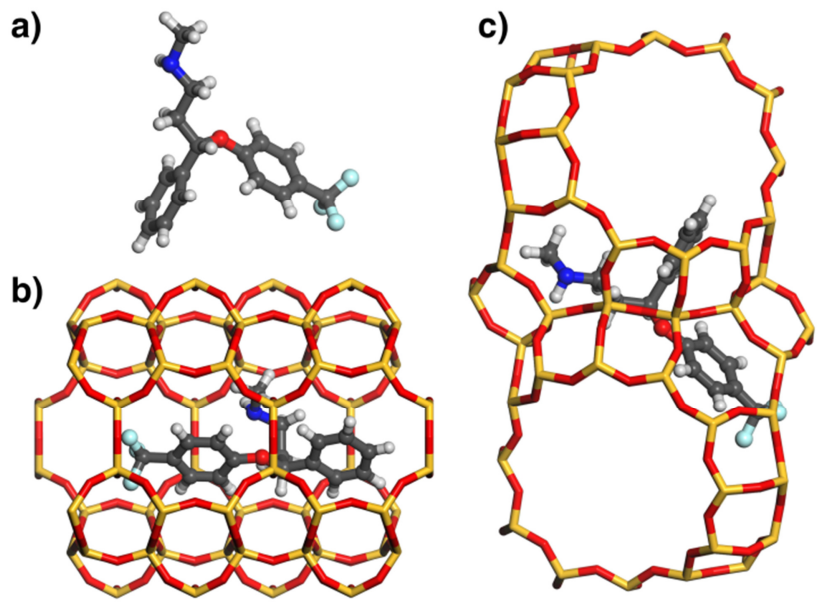

Figure 2: a) DREIDING-optimised structure of fluoxetine. b) Lowest-energy configuration of fluoxetine in MOR. In the projection, the $12 \mathrm{MR}$ channels run from left to right, and the $8 \mathrm{MR}$ windows lie in the projection plane. c) Lowest-energy configuration of fluoxetine in FAU. Two adjacent supercages connected by a $12 \mathrm{MR}$ window are shown. 
While one can already estimate from the visualisation of the low-energy configurations that there are many close contacts between fluoxetine and framework atoms for both zeolites, a more quantitative assessment can be made by looking at the distribution of interatomic distances. For this analysis, histograms of the distance between framework atoms and non-hydrogen atoms of fluoxetine were compiled (hydrogen atoms were not considered because their contribution to vdW interactions is small). The distance distribution visualised in Figure 3 clearly shows a considerable number of interatomic contacts between $~ 3.5$ and $5 \AA$ for both frameworks (the larger number of distances between 4 and $5 \AA$ for MOR can be explained with the confinement of fluoxetine to a 1D channel, compared to the relatively open supercage of FAU). As the minima of the $L J$ pair potentials (derived from DREIDING parameters using Lorentz-Berhelot mixing rules) are in the range of 3.4 to $3.6 \AA$ for contacts between adsorbate $\mathrm{C}, \mathrm{N}, \mathrm{O}$, and $\mathrm{F}$ atoms and framework oxygen atoms, and in the range of 3.9 to $4.1 \AA$ for contacts to framework Si atoms, contacts from $\sim 3.4$ to $\sim 4.2 \AA$ will make the most important attractive contribution to the total vdW interaction.
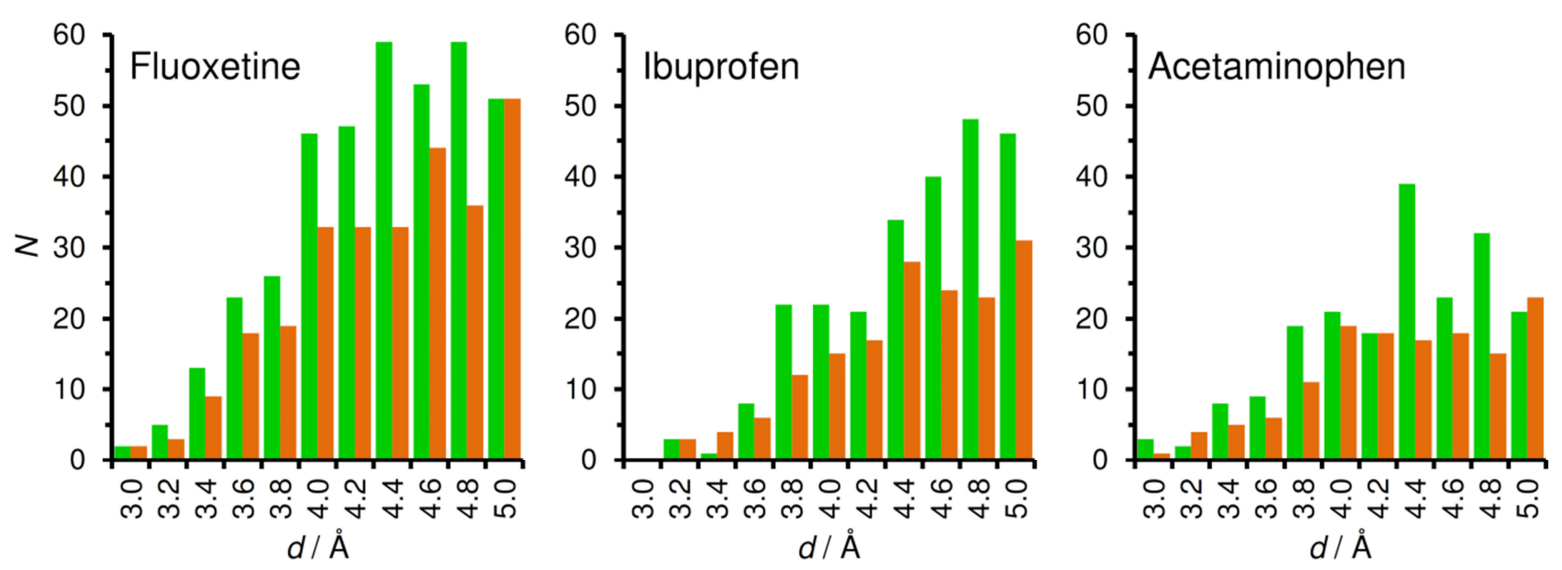

Figure 3: Distance distribution in lowest-energy configurations of fluoxetine, ibuprofen, and acetaminophen in MOR (green columns) and FAU (orange columns). Each column corresponds to the number of framework-guest contacts within an interval of $d \pm 0.1 \AA$. For example, a column of height 2 at $d=3.0 \AA$ r represents two framework-guest contacts having a length between 2.9 and $3.1 \AA$.

In the lowest-energy configuration of ibuprofen adsorbed in MOR (Figure 4), the phenyl ring lies above one of the 8MR side pockets and two of the methyl groups point into other side pockets. In addition, there is a hydrogen bond from the carboxylic acid group to a framework oxygen atom (the DREIDING force field includes an explicit term for hydrogen bonds which was included in the optimisations of low-energy configurations). Such a hydrogen bond is also present in FAU, where the carboxylic acid group is located in a $12 \mathrm{MR}$ window. Here, the central phenyl ring lies roughly above one $6 \mathrm{MR}$ of the framework, which is favourable in terms of vdW interactions, whereas the remainder of the ibuprofen molecule cannot arrange in a way that results in many close contacts. The distance distributions (Figure 3) overall show fewer framework-guest contacts at any given distance than found above for fluoxetine, which is straightforwardly explained with the smaller number of nonhydrogen atoms in the ibuprofen molecule. It is also apparent that the number of contacts in the distance range of strongest attraction (3.4 to $4.2 \AA$ ) is significantly larger for MOR than for FAU, explaining why the computed interaction energy is more than $-70 \mathrm{~kJ} / \mathrm{mol}$ more negative for the former system. 
a)

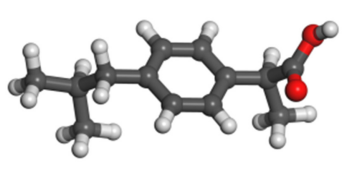

b)

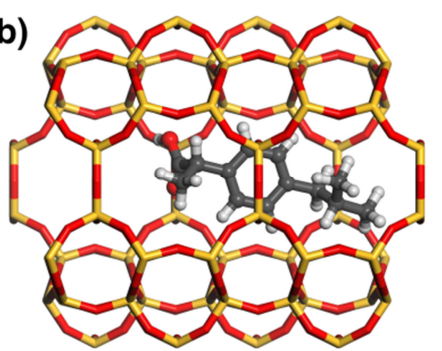

c)

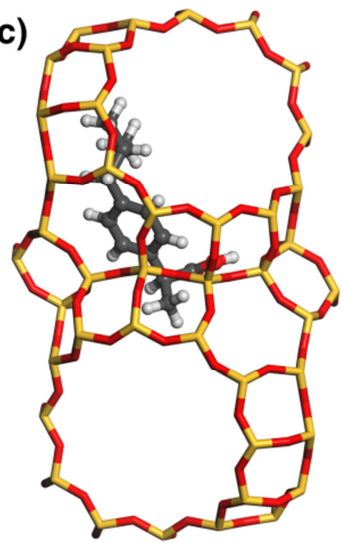

Figure 4: a) DREIDING-optimised structure of ibuprofen. b) and c) Lowest-energy configurations of ibuprofen in MOR and FAU.

Similar to ibuprofen, acetaminophen also forms a hydrogen bond from the hydroxyl group to a framework oxygen atom of MOR. However, this smaller and more rigid molecule fills the 12MR channel much less efficiently than fluoxetine or ibuprofen, leading to a displacement towards one side of the channel (Figure 5). As a consequence, attractive vdW interactions with the framework are weaker. This is corroborated by the distance distribution: While the number of contacts in the range up to $4 \AA$ is actually quite similar to that found for ibuprofen in MOR, there are fewer contacts between 4 and $5 \AA$, because the atoms at the opposite channel wall lie at distances above $6 \AA$ due to the off-centre displacement. Apparently, these framework-guest contacts of intermediate length (above the sum of vdW radii) make an important contribution to the overall interaction energy. The lowest-energy configuration of acetaminophen in FAU is similar to that of ibuprofen in this zeolite: The phenyl moiety lies above a $6 \mathrm{MR}$, but the rest of the molecule cannot establish many close contacts with the framework.

a)

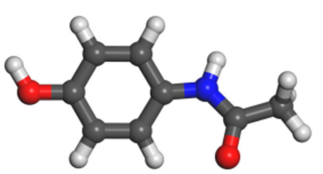

b)

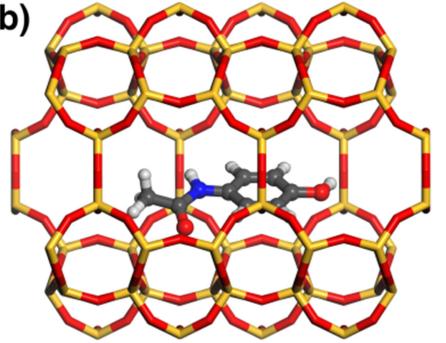

c)

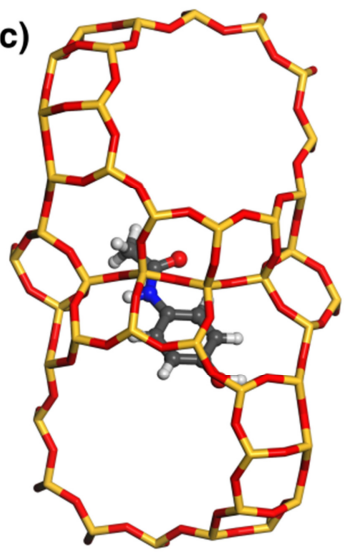

Figure 5: a) DREIDING-optimised structure of acetaminophen. b) and c) Lowest-energy configurations of acetaminophen in MOR and FAU. 


\section{Adsorption of acetaminophen in various zeolites}

In order to illustrate how molecular simulations could be employed in a predictive fashion, the adsorption of acetaminophen in 11 other zeolite frameworks was studied. The set of zeolites was selected on the basis of the following two criteria: First, every framework should be available in allsilica or at least high-silica form (the acronyms of representative zeolites are included in Table 1). Second, the framework should possess at least 10MR windows, as it can be expected that the acetaminophen molecule cannot pass through smaller rings.

The resulting values of $E_{\mathrm{zg}}$ are listed in Table 3 . First of all, it is noteworthy that no $E_{\mathrm{zg}}$ value below $-200 \mathrm{~kJ} / \mathrm{mol}$ is found for any zeolite, whereas it was observed above that high removal efficiencies occur essentially exclusively for adsorbent-adsorbate combinations having an interaction energy of this magnitude. However, values between -195 and $-181 \mathrm{~kJ} / \mathrm{mol}$ are obtained for four zeolites having $10 \mathrm{MR}$ channel systems, FER, MEL, MFI, and MWW. While it appears plausible that the smaller channel diameter affords a larger number of close contacts between the adsorbed molecule and the framework, leading to stronger vdW interactions, it is also worth noting that there are some zeolites with 10MR channels for which the interaction is distinctly weaker (MTT, TON). Furthermore, the dimensionality of the channel system does not seem to play an important role, as the frameworks in which the interaction is strongest have 1D (FER), 2D (MWW), and 3D (MEL, MFI) channel systems. Taken together, the simulation results indicate that zeolites with 10MR pores should be more promising for the removal of acetaminophen from aqueous solution than the $12 \mathrm{MR}$ systems studied by Rossner et al. It has to be kept in mind that real-world wastewater treatment applications would usually require the adsorption of a mixture of pollutants. The larger molecules included in the present work would not be able to fit into 10MR channels. As a consequence, either a combination of adsorbents with different channel systems or the use of one zeolite having different types of channels might be required to remove a broad range of organic contaminants.

Table 3: $E_{\mathrm{zg}}$ values obtained for acetaminophen adsorption in various zeolites.

\begin{tabular}{|c|c|c|}
\hline FTC & $\begin{array}{c}\text { Channel system } \\
\text { (only } \geq 10 \mathrm{MR} \text { ) and } \\
\text { dimensionality }\end{array}$ & $\begin{array}{c}E_{\mathrm{zg}} \text { (acetam.) } \\
{[\mathrm{kJ} / \mathrm{mol}]}\end{array}$ \\
\hline MOR & 12MR (1D) & -152 \\
\hline FAU & $12 \mathrm{MR}(3 \mathrm{D})$ & -113 \\
\hline $\mathrm{AFI}$ & 12MR (1D) & -146 \\
\hline BEA & $12 \mathrm{MR}(3 \mathrm{D})$ & -151 \\
\hline EUO & 10MR (1D) & -170 \\
\hline FER & 10MR (1D) & -194 \\
\hline MEI & $12 \mathrm{MR}$ (1D) & -146 \\
\hline MEL & 10MR (3D) & -183 \\
\hline MFI & 10MR (3D) & -185 \\
\hline MTT & 10MR (1D) & -165 \\
\hline MTW & $12 \mathrm{MR}(1 \mathrm{D})$ & -175 \\
\hline MWW & 10MR (2D) & -181 \\
\hline TON & 10MR (1D) & -167 \\
\hline
\end{tabular}


Figure 6a visualises the lowest-energy configuration of acetaminophen in the FER structure. The acetaminophen molecule is located close to the centre of the 10MR channels, pointing along the running direction of the channels, with the phenyl moiety lying directly above a six-ring that is part of the channel wall. A comparison of the distance distribution of framework-guest contacts of FER to that of MOR (Figure $6 \mathrm{~b}$ ) reveals a much larger number of contacts in the distance range between 3.4 and $4.2 \AA$, corroborating the better "fit" of the acetaminophen molecule into these narrower channels. While no experimental studies of pharmaceutical adsorption in all-silica FER have been reported, the adsorption of acetaminophen in MFI-type ZSM- 5 has been investigated by De Ridder et al.[31] They observed negligible uptake of acetaminophen in this system, at variance with the rather strong interaction obtained in the simulations. This discrepancy can possibly be explained with the reduced hydrophobicity of the $\mathrm{ZSM}-5$ adsorbent $(\mathrm{Si} / \mathrm{Al}=40)$, which is likely to cause a non-negligible competitive adsorption of water.

a)

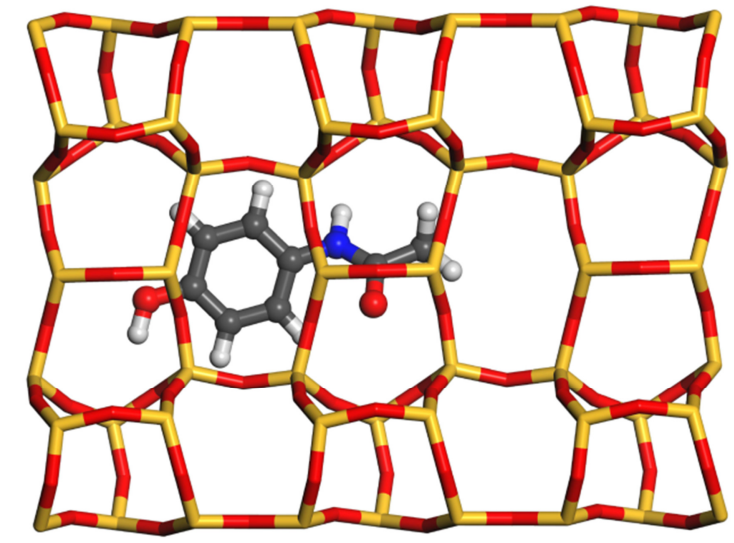

b) 60

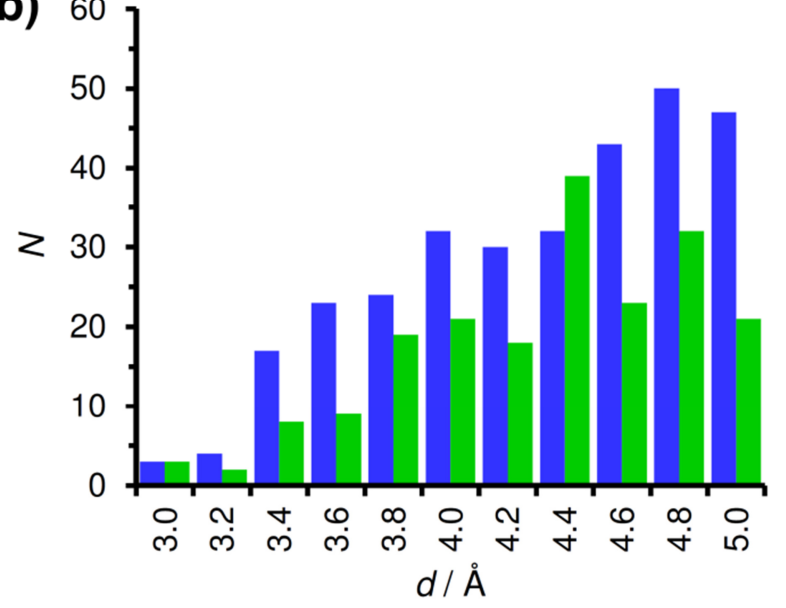

Figure 6: a) Lowest-energy configurations of acetaminophen in FER. The 10MR channels run from left to right. b) Distribution of interatomic contacts for FER (blue columns) and comparison to MOR (green columns). 


\section{Discussion}

As mentioned briefly in the Introduction, the approach employed in the present work makes use of a number of simplifications, which are summarised in the following:

- The removal efficiency (in the limit of low coverage) is determined by the enthalpy of transfer from aqueous solution to the adsorbed state in the zeolite pore. An actual simulation of this adsorption process would have to use the hydrated pollutant molecule as reference state. While such simulations are possible (for example, Bai et al. used Gibbs ensemble $M C$ simulations to study the adsorption of glucose into zeolite beta from aqueous solution[58]), they are very time-consuming, especially for complex molecules. In the present study, interaction energies $E_{\mathrm{zg}}$ were calculated using the isolated (not hydrated) molecule as reference state. Clearly, this is a rather drastic simplification. One cannot even expect that $E_{\mathrm{zg}}$ and the enthalpy of transfer are directly correlated, as the enthalpy of transfer also depends on the interactions between a pollutant molecule and its hydration shell, i.e., the hydration free energy.[28]

- The range of $\mathrm{p} K_{\mathrm{a}}$ values, summarised in Table 1 of ref. [30], shows that at least some of the pollutants studied are dominantly anionic at near-neutral $\mathrm{pH}$ (e.g., diclofenac: $\mathrm{p} K_{\mathrm{a}}=4.2$, ibuprofen: $\left.\mathrm{p} K_{\mathrm{a}}=4.9\right)$. In the simulations, it was assumed that neutral molecules are adsorbed in the zeolites, and electrostatic interactions were neglected completely. In other words, it was assumed that the adsorption process is dominated by vdW interactions.

- While several local minima were sampled during the simulations, only the energy of the lowest-energy configuration was used in the analysis. This is, again, a simplification, as it has to be expected that several low-energy configurations will coexist at room temperature. This concerns both different conformations of the adsorbate and different adsorption sites.

- Although it has been demonstrated experimentally that the adsorption of pharmaceuticals leads to distortions of the zeolite framework, $[32,35,36,40]$ completely rigid zeolite models were used in the simulations. Furthermore, the adsorbents were idealised as defect-free allsilica zeolites.

- Finally, the simulations only considered adsorption of individual pollutant molecules, ignoring the potential influence of guest-guest interactions and of the coadsorption of water.

In the light of this long list of inherent simplifications, it might appear surprising that the simulation approach is nevertheless able to correctly identify the large majority of adsorbent-adsorbate combinations for which high removal efficiencies have been found experimentally. The analysis above has shown that the zeolite-guest interaction energy is determined largely by the ability of the guest molecule to maximise the number of favourable vdW contacts with the framework atoms, i.e., the "fit" of the pollutant into the zeolite pores. This fit can be predicted reasonably well using the simple vdW-only picture employed, as has been done previously in computational studies of the stabilisation of zeolite frameworks by OSDAs.[51-57] As a consequence, it appears that the interaction energy $E_{z \mathrm{~g}}$ could be used in a predictive fashion to identify adsorbents with a high affinity towards a given pollutant. However, it needs to be emphasised that the zeolite-guest interaction energy is an artificial quantity that has no directly measurable experimental analogue, and that any simulation approach aiming at a physically accurate description of the actual adsorption process would necessarily have to be much more complex. 
While the present work relied exclusively on a comparison of the simulation results to experimental removal efficiencies reported by Rossner et al., it has to be noted that other authors have studied the adsorption of some of these pollutants onto the same zeolites. For example, Martucci et al. investigated the adsorption of carbamazepine in both MOR and FAU.[35] Their observation of a predominant adsorption of carbamazepine at the external surface of MOR agrees with the difficulties of inserting this molecule into the MOR channels using MC simulations. With regard to FAU, Martucci et al. observed high carbamazepine removal efficiencies in the $\mathrm{mg} / \mathrm{L}$ and $\mu \mathrm{g} / \mathrm{L}$ ranges, at variance with the findings of Rossner et al., who studied a lower concentration ( $600 \mathrm{ng} / \mathrm{L}$ ). Potentially, this difference could be attributed to attractive guest-guest interactions, which have been demonstrated to be significant for several other pharmaceuticals adsorbed in FAU.[33, 37] Because the simulations in the present work considered only one molecule per simulation cell, guest-guest interactions were not evaluated. Another discrepancy among experimental works exists for sulfamethoxazole, where Fukahori et al. and Blasioli et al. reported a high affinity of FAU-type adsorbents towards this pharmaceutical (again, at higher loadings),[39, 40] in disagreement with the negligible removal efficiencies observed by Rossner et al. While the present work cannot resolve these discrepancies, they highlight that a thorough validation of any computational approach will also require further experimental characterisation efforts.

If the dimensions of the guest molecule approach the diameter of channels or pore-connecting windows, the diffusion of the guest species through the pores will be impeded. Diffusional limitations have been observed experimentally in some cases, for example for sulfamethoxazole in zeolite MOR.[40] The limited ability of sulfamethoxazole to diffuse through the pores of MOR might be one potential explanation for the discrepancy between simulation and experiment, observed above, but other origins cannot be ruled out. The ability of force-field based MD simulations to predict the qualitatively different diffusion behaviour of two pharmaceuticals in the pores of a zeolite beta adsorbent has been demonstrated by Fatouros et al.[59] However, if the diffusion is slow, but nonnegligible, the timescale that is accessible with standard MD methods can be too short to capture the diffusion processes, and rare-event simulations methods may be needed.[43]

\section{Conclusions and Outlook}

Molecular simulations performed for various organic pollutants in two zeolites reveal that the zeolite-guest interaction energy of the lowest-energy configuration can potentially be used to predict the removal efficiency. Adsorbent-adsorbate combinations for which an essentially quantitative removal was observed in previous experimental work are, in all cases, characterised by a zeoliteguest interaction energy of at least $-200 \mathrm{~kJ} / \mathrm{mol}$. Clearly, the importance of this particular "threshold" energy value should not be overestimated, as it will depend on the choice of force field and various other factors. Rather than aiming at a quantitative prediction of any directly measurable physical quantity, the main aim of the present work was to establish the relative robustness of a simple approach: Despite employing a generic force field without any system-specific parameterisation, and despite the various simplifications mentioned in the Discussion, the simulations can be useful for an initial "screening" of adsorbents that aims to reduce the number of potential adsorbent-adsorbate combinations prior to carrying out experimental work or more detailed computations. In the view of the huge number of pharmaceutical pollutants that are currently found in the environment, and the structural variability of zeolites, such screening strategies have considerable potential to facilitate the 
development of new adsorbents for wastewater treatment. Furthermore, similar modelling approaches can also find application in related fields, e.g., with regard to the use of zeolites as host materials in drug delivery.[59, 70, 71]

In the light of the various simplifications made in the present work, discussed above, it is quite clear that the approach could be improved in various ways. Such improvements could include a) the use of another force field that is more specifically designed for the modelling of pharmaceutical compounds[72], b) a calculation of $E_{z \mathrm{~g}}$ that takes into account several local minima, e.g., by using a Boltzmann averaging over different configurations, c) the development of approximate ways to include the transfer from solution to the adsorbed phase, e.g., by taking into account the hydration free energy computed using the same force field. A combination of force field methods with electronic structure calculations should be particularly helpful to develop an increasingly accurate atomic-level picture.

\section{Acknowledgements}

This research was funded by the Deutsche Forschungsgemeinschaft (DFG-German Research Foundation), project number 389577027 (FI 1800/5-1). The author would like to thank Guido Cerri (Sassari) for insightful discussions and for a critical reading of a draft version.

\section{Supporting Information}

- DREIDING-optimised molecular structures of pollutants (in MDL MOL format)

- SLC-optimised structures of zeolite adsorbents (in CIF format) 


\section{References}

1. aus der Beek T, Weber F-A, Bergmann A, Hickmann S, Ebert I, Hein A, Küster A (2016) Pharmaceuticals in the environment-Global occurrences and perspectives. Environ Toxicol Chem 35:823-835 . https://doi.org/10.1002/etc.3339

2. Ebele AJ, Abou-Elwafa Abdallah M, Harrad S (2017) Pharmaceuticals and personal care products (PPCPs) in the freshwater aquatic environment. Emerg Contam 3:1-16. https://doi.org/10.1016/j.emcon.2016.12.004

3. Petrie B, Barden R, Kasprzyk-Hordern B (2015) A review on emerging contaminants in wastewaters and the environment: Current knowledge, understudied areas and recommendations for future monitoring. Water Res 72:3-27 . https://doi.org/10.1016/j.watres.2014.08.053

4. Jelic A, Gros M, Ginebreda A, Cespedes-Sánchez R, Ventura F, Petrovic M, Barcelo D (2011) Occurrence, partition and removal of pharmaceuticals in sewage water and sludge during wastewater treatment. Water Res 45:1165-1176. https://doi.org/10.1016/j.watres.2010.11.010

5. Boxall ABA, Rudd MA, Brooks BW, Caldwell DJ, Choi K, Hickmann S, Innes E, Ostapyk K, Staveley JP, Verslycke T, Ankley GT, Beazley KF, Belanger SE, Berninger JP, Carriquiriborde P, Coors A, DeLeo PC, Dyer SD, Ericson JF, Gagné F, Giesy JP, Gouin T, Hallstrom L, Karlsson M V., Larsson DGJ, Lazorchak JM, Mastrocco F, McLaughlin A, McMaster ME, Meyerhoff RD, Moore R, Parrott JL, Snape JR, Murray-Smith R, Servos MR, Sibley PK, Straub JO, Szabo ND, Topp E, Tetreault GR, Trudeau VL, Van Der Kraak G (2012) Pharmaceuticals and Personal Care Products in the Environment: What Are the Big Questions? Environ Health Perspect 120:1221-1229 . https://doi.org/10.1289/ehp.1104477

6. Verlicchi P, Al Aukidy M, Zambello E (2012) Occurrence of pharmaceutical compounds in urban wastewater: Removal, mass load and environmental risk after a secondary treatment-A review. Sci Total Environ 429:123-155 . https://doi.org/10.1016/j.scitotenv.2012.04.028

7. Luo Y, Guo W, Ngo HH, Nghiem LD, Hai Fl, Zhang J, Liang S, Wang XC (2014) A review on the occurrence of micropollutants in the aquatic environment and their fate and removal during wastewater treatment. Sci Total Environ 473-474:619-641 . https://doi.org/10.1016/j.scitotenv.2013.12.065

8. Archer E, Petrie B, Kasprzyk-Hordern B, Wolfaardt GM (2017) The fate of pharmaceuticals and personal care products (PPCPs), endocrine disrupting contaminants (EDCs), metabolites and illicit drugs in a WWTW and environmental waters. Chemosphere 174:437-446 . https://doi.org/10.1016/j.chemosphere.2017.01.101

9. Yang Y, Ok YS, Kim K, Kwon EE, Tsang YF (2017) Occurrences and removal of pharmaceuticals and personal care products (PPCPs) in drinking water and water/sewage treatment plants: A review. Sci Total Environ 596-597:303-320 . https://doi.org/10.1016/j.scitotenv.2017.04.102

10. Kim K-R, Owens G, Kwon S-I, So K-H, Lee D-B, Ok YS (2011) Occurrence and Environmental Fate of Veterinary Antibiotics in the Terrestrial Environment. Water, Air, Soil Pollut 214:163174 . https://doi.org/10.1007/s11270-010-0412-2 
11. González-Alonso S, Merino LM, Esteban S, López de Alda M, Barceló D, Durán JJ, LópezMartínez J, Aceña J, Pérez S, Mastroianni N, Silva A, Catalá M, Valcárcel Y (2017) Occurrence of pharmaceutical, recreational and psychotropic drug residues in surface water on the northern Antarctic Peninsula region. Environ Pollut 229:241-254 .

https://doi.org/10.1016/j.envpol.2017.05.060

12. Karkman A, Do TT, Walsh F, Virta MPJ (2018) Antibiotic-Resistance Genes in Waste Water. Trends Microbiol 26:220-228 . https://doi.org/10.1016/j.tim.2017.09.005

13. Ahmed MB, Zhou JL, Ngo HH, Guo W (2015) Adsorptive removal of antibiotics from water and wastewater: Progress and challenges. Sci Total Environ 532:112-126 . https://doi.org/10.1016/j.scitotenv.2015.05.130

14. Ahmed MB, Zhou JL, Ngo HH, Guo W, Thomaidis NS, Xu J (2017) Progress in the biological and chemical treatment technologies for emerging contaminant removal from wastewater: $A$ critical review. J Hazard Mater 323:274-298 . https://doi.org/10.1016/j.jhazmat.2016.04.045

15. Richardson SD, Kimura SY (2017) Emerging environmental contaminants: Challenges facing our next generation and potential engineering solutions. Environ Technol Innov 8:40-56 . https://doi.org/10.1016/j.eti.2017.04.002

16. De Andrade JR, Oliveira MF, Da Silva MGC, Vieira MGA (2018) Adsorption of Pharmaceuticals from Water and Wastewater Using Nonconventional Low-Cost Materials: A Review. Ind Eng Chem Res 57:3103-3127 . https://doi.org/10.1021/acs.iecr.7b05137

17. Patel M, Kumar R, Kishor K, Mlsna T, Pittman CU, Mohan D (2019) Pharmaceuticals of emerging concern in aquatic systems: Chemistry, occurrence, effects, and removal methods. Chem Rev 119:3510-3673 . https://doi.org/10.1021/acs.chemrev.8b00299

18. Grover DP, Zhou JL, Frickers PE, Readman JW (2011) Improved removal of estrogenic and pharmaceutical compounds in sewage effluent by full scale granular activated carbon: Impact on receiving river water. J Hazard Mater 185:1005-1011 .

https://doi.org/10.1016/j.jhazmat.2010.10.005

19. Delgado LF, Charles P, Glucina K, Morlay C (2012) The removal of endocrine disrupting compounds, pharmaceutically activated compounds and cyanobacterial toxins during drinking water preparation using activated carbon-A review. Sci Total Environ 435-436:509-525 . https://doi.org/10.1016/j.scitotenv.2012.07.046

20. Guo Y, Chen B, Liu D, Huang W, Sun Y, Zhao Y (2018) Removal of antibiotics from aqueous solution using silicon-based materials. An overview. Environ Technol Rev 7:177-198 . https://doi.org/10.1080/21622515.2018.1482374

21. Rakić V, Rajić N, Daković A, Auroux A (2013) The adsorption of salicylic acid, acetylsalicylic acid and atenolol from aqueous solutions onto natural zeolites and clays: Clinoptilolite, bentonite and kaolin. Microporous Mesoporous Mater 166:185-194 .

https://doi.org/10.1016/j.micromeso.2012.04.049

22. Rivagli E, Pastorello A, Sturini M, Maraschi F, Speltini A, Zampori L, Setti M, Malavasi L, Profumo A (2014) Clay minerals for adsorption of veterinary FQs: Behavior and modeling. J Environ Chem Eng 2:738-744 . https://doi.org/10.1016/j.jece.2013.11.017

23. Dordio AV, Miranda S, Prates Ramalho JP, Carvalho AJP (2017) Mechanisms of removal of three widespread pharmaceuticals by two clay materials. J Hazard Mater 323:575-583 . https://doi.org/10.1016/j.jhazmat.2016.05.091 
24. Bui TX, Choi H (2009) Adsorptive removal of selected pharmaceuticals by mesoporous silica SBA-15. J Hazard Mater 168:602-608 . https://doi.org/10.1016/j.jhazmat.2009.02.072

25. Bui TX, Choi H (2010) Influence of ionic strength, anions, cations, and natural organic matter on the adsorption of pharmaceuticals to silica. Chemosphere 80:681-686 .

https://doi.org/10.1016/j.chemosphere.2010.05.046

26. Ötker HM, Akmehmet-Balcıoğlu I (2005) Adsorption and degradation of enrofloxacin, a veterinary antibiotic on natural zeolite. J Hazard Mater 122:251-258 .

https://doi.org/10.1016/j.jhazmat.2005.03.005

27. Lye JWP, Saman N, Sharuddin SSN, Othman NS, Mohtar SS, Md Noor AM, Buhari J, Cheu SC, Kong H, Mat H (2017) Removal Performance of Tetracycline and Oxytetracycline From Aqueous Solution Via Natural Zeolites: An Equilibrium and Kinetic Study. CLEAN - Soil, Air, Water 45:1600260 . https://doi.org/10.1002/clen.201600260

28. Jiang N, Shang R, Heijman SGJ, Rietveld LC (2018) High-silica zeolites for adsorption of organic micro-pollutants in water treatment: A review. Water Res 144:145-161.

https://doi.org/10.1016/j.watres.2018.07.017

29. Baerlocher C, McCusker LB (2018) Database of Zeolite Structures. http://www.izastructure.org/databases/

30. Rossner A, Snyder SA, Knappe DRU (2009) Removal of emerging contaminants of concern by alternative adsorbents. Water Res 43:3787-3796 .

https://doi.org/10.1016/j.watres.2009.06.009

31. De Ridder DJ, Verberk JQJC, Heijman SGJ, Amy GL, Van Dijk JC (2012) Zeolites for nitrosamine and pharmaceutical removal from demineralised and surface water: Mechanisms and efficacy. Sep Purif Technol 89:71-77 . https://doi.org/10.1016/j.seppur.2012.01.025

32. Braschi I, Blasioli S, Gigli L, Gessa CE, Alberti A, Martucci A (2010) Removal of sulfonamide antibiotics from water: Evidence of adsorption into an organophilic zeolite $Y$ by its structural modifications. J Hazard Mater 178:218-225 . https://doi.org/10.1016/j.jhazmat.2010.01.066

33. Braschi I, Gatti G, Paul G, Gessa CE, Cossi M, Marchese L (2010) Sulfonamide antibiotics embedded in high silica zeolite Y: A combined experimental and theoretical study of hostguest and guest-guest interactions. Langmuir 26:9524-9532 . https://doi.org/10.1021/la9049132

34. Fukahori S, Fujiwara T, Ito R, Funamizu N (2011) pH-Dependent adsorption of sulfa drugs on high silica zeolite: Modeling and kinetic study. Desalination 275:237-242 . https://doi.org/10.1016/j.desal.2011.03.006

35. Martucci A, Pasti L, Marchetti N, Cavazzini A, Dondi F, Alberti A (2012) Adsorption of pharmaceuticals from aqueous solutions on synthetic zeolites. Microporous Mesoporous Mater 148:174-183 . https://doi.org/10.1016/j.micromeso.2011.07.009

36. Martucci A, Cremonini MA, Blasioli S, Gigli L, Gatti G, Marchese L, Braschi I (2013) Adsorption and reaction of sulfachloropyridazine sulfonamide antibiotic on a high silica mordenite: $A$ structural and spectroscopic combined study. Microporous Mesoporous Mater 170:274-286 . https://doi.org/10.1016/j.micromeso.2012.11.031

37. Braschi I, Paul G, Gatti G, Cossi M, Marchese L (2013) Embedding monomers and dimers of sulfonamide antibiotics into high silica zeolite $\mathrm{Y}$ : An experimental and computational study of the tautomeric forms involved. RSC Adv 3:7427-7437 . https://doi.org/10.1039/c3ra22290j 
38. Pasti L, Sarti E, Cavazzini A, Marchetti N, Dondi F, Martucci A (2013) Factors affecting drug adsorption on beta zeolites. J Sep Sci 36:1604-1611 . https://doi.org/10.1002/jssc.201201142

39. Fukahori S, Fujiwara T, Funamizu N, Matsukawa K, Ito R (2013) Adsorptive removal of sulfonamide antibiotics in livestock urine using the high-silica zeolite HSZ-385. Water Sci Technol 67:319-325 . https://doi.org/10.2166/wst.2012.513

40. Blasioli S, Martucci A, Paul G, Gigli L, Cossi M, Johnston CT, Marchese L, Braschi I (2014) Removal of sulfamethoxazole sulfonamide antibiotic from water by high silica zeolites: A study of the involved host-guest interactions by a combined structural, spectroscopic, and computational approach. J Colloid Interface Sci 419:148-159 .

https://doi.org/10.1016/j.jcis.2013.12.039

41. Braschi I, Martucci A, Blasioli S, Mzini LL, Ciavatta C, Cossi M (2016) Effect of humic monomers on the adsorption of sulfamethoxazole sulfonamide antibiotic into a high silica zeolite $\mathrm{Y}$ : An interdisciplinary study. Chemosphere 155:444-452 .

https://doi.org/10.1016/j.chemosphere.2016.04.008

42. Braschi I, Blasioli S, Buscaroli E, Montecchio D, Martucci A (2016) Physicochemical regeneration of high silica zeolite $Y$ used to clean-up water polluted with sulfonamide antibiotics. J Environ Sci 43:302-312 . https://doi.org/10.1016/j.jes.2015.07.017

43. Smit B, Maesen TLM (2008) Molecular simulations of zeolites: adsorption, diffusion, and shape selectivity. Chem Rev 108:4125-4184 . https://doi.org/10.1021/cr8002642

44. Van Speybroeck V, Hemelsoet K, Joos L, Waroquier M, Bell RG, Catlow CRA (2015) Advances in theory and their application within the field of zeolite chemistry. Chem Soc Rev 44:7044-7111 . https://doi.org/10.1039/C5CS00029G

45. Chempath S, Snurr RQ, Low JJ (2004) Molecular Modeling of Binary Liquid-Phase Adsorption of Aromatics in Silicalite. AIChE J 50:463-469 . https://doi.org/10.1002/aic.10040

46. Boulet P, Narasimhan L, Berg'e-Lefranc D, Kuchta B, Schäf O, Denoyel R (2009) Adsorption into the MFI zeolite of aromatic molecule of biological relevance. Investigations by Monte Carlo simulations. J Mol Model 15:573-9 . https://doi.org/10.1007/s00894-008-0417-6

47. Narasimhan L, Boulet P, Kuchta B, Vagner C, Schäf O, Denoyel R (2010) Adsorption of paracresol in silicalite-1 and pure silica faujasite. A comparison study using molecular simulation. Appl Surf Sci 256:5470-5474 . https://doi.org/10.1016/j.apsusc.2009.12.142

48. Torres-Knoop A, Heinen J, Krishna R, Dubbeldam D (2015) Entropic Separation of Styrene/Ethylbenzene Mixtures by Exploitation of Subtle Differences in Molecular Configurations in Ordered Crystalline Nanoporous Adsorbents. Langmuir 31:3771-3778 . https://doi.org/10.1021/acs.langmuir.5b00363

49. Toda J, Corma A, Sastre G (2016) Diffusion of Trimethylbenzenes and Xylenes in Zeolites with 12- and 10-Ring Channels as Catalyst for Toluene-Trimethylbenzene Transalkylation. J Phys Chem C 120:16668-16680 . https://doi.org/10.1021/acs.jpcc.6b03806

50. Randrianandraina J, Deroche I, Bullot L, Stephan R, Hanf M, Chaplais G, Daou TJ, SimonMasseron A, Patarin J, Sonnet P (2018) Adsorption of Polychlorinated Aromatics in EMT-Type Zeolites: A Combined Experimental-Simulation Approach. J Phys Chem C 122:12731-12741 . https://doi.org/10.1021/acs.jpcc.8b02115 
51. Pophale R, Daeyaert F, Deem MW (2013) Computational prediction of chemically synthesizable organic structure directing agents for zeolites. J Mater Chem A 1:6750-6760 . https://doi.org/10.1039/c3ta10626h

52. Schmidt JE, Deem MW, Davis ME (2014) Synthesis of a Specified, Silica Molecular Sieve by Using Computationally Predicted Organic Structure-Directing Agents. Angew Chem Int Ed Engl 53:8372-8374 . https://doi.org/10.1002/anie.201404076

53. Schmidt JE, Deem MW, Lew C, Davis TM (2015) Computationally-Guided Synthesis of the 8Ring Zeolite AEI. Top Catal 58:410-415 . https://doi.org/10.1007/s11244-015-0381-1

54. Davis TM, Liu AT, Lew CM, Xie D, Benin Al, Elomari S, Zones SI, Deem MW (2016) Computationally Guided Synthesis of SSZ-52: A Zeolite for Engine Exhaust Clean-up. Chem Mater 28:708-711 . https://doi.org/10.1021/acs.chemmater.5b04578

55. Lu P, Mayoral A, Gómez-Hortigüela L, Zhang Y, Camblor MA (2019) Synthesis of 3D Large-Pore Germanosilicate Zeolites Using Imidazolium-Based Long Dications. Chem Mater 31:5484-5493 . https://doi.org/10.1021/acs.chemmater.9b00959

56. Gálvez-Llompart M, Cantín A, Rey F, Sastre G (2019) Computational screening of structure directing agents for the synthesis of zeolites. A simplified model. Zeitschrift fur Krist - Cryst Mater 234:451-460 . https://doi.org/10.1515/zkri-2018-2132

57. Daeyaert F, Deem MW (2019) Design of Organic Structure-Directing Agents for the Controlled Synthesis of Zeolites for Use in Carbon Dioxide/Methane Membrane Separations. Chempluschem 10.1002/cplu.201900679 . https://doi.org/10.1002/cplu.201900679

58. Bai P, Siepmann JI, Deem MW (2013) Adsorption of glucose into zeolite beta from aqueous solution. AIChE J 59:3523-3529 . https://doi.org/10.1002/aic.14104

59. Fatouros DG, Douroumis D, Nikolakis V, Ntais S, Moschovi AM, Trivedi V, Khima B, Roldo M, Nazar H, Cox PA (2011) In vitro and in silico investigations of drug delivery via zeolite BEA. J Mater Chem 21:7789-7794 . https://doi.org/10.1039/c1jm10204d

60. de Voogt P, Janex-Habibi M-L, Sacher F, Puijker L, Mons M (2009) Development of a common priority list of pharmaceuticals relevant for the water cycle. Water Sci Technol 59:39-46 . https://doi.org/10.2166/wst.2009.764

61. Gale JD, Rohl AL (2003) The General Utility Lattice Program (GULP). Mol Simul 29:291-341 . https://doi.org/10.1080/0892702031000104887

62. Sanders MJ, Leslie M, Catlow CRA (1984) Interatomic potentials for SiO2. J Chem Soc Chem Commun 1271-1273 . https://doi.org/10.1039/c39840001271

63. Combariza AF, Gomez DA, Sastre G (2013) Simulating the properties of small pore silica zeolites using interatomic potentials. Chem Soc Rev 42:114-127 . https://doi.org/10.1039/c2cs35243e

64. Fischer M, Evers FO, Formalik F, Olejniczak A (2016) Benchmarking DFT-GGA calculations for the structure optimisation of neutral-framework zeotypes. Theor Chem Acc 135:257 . https://doi.org/10.1007/s00214-016-2014-6

65. Baur WH, Fischer RX (2010) ZeoBase, a new kind of crystal structure database. In: De Frede A (ed) Proc. 16th Int. Zeolite Conf. Sorrento, Italy, p 457 
66. Kim S, Chen J, Cheng T, Gindulyte A, He J, He S, Li Q, Shoemaker BA, Thiessen PA, Yu B, Zaslavsky L, Zhang J, Bolton EE (2019) PubChem 2019 update: improved access to chemical data. Nucleic Acids Res 47:D1102-D1109 . https://doi.org/10.1093/nar/gky1033

67. Hastings J, Owen G, Dekker A, Ennis M, Kale N, Muthukrishnan V, Turner S, Swainston N, Mendes P, Steinbeck C (2016) ChEBI in 2016: Improved services and an expanding collection of metabolites. Nucleic Acids Res 44:D1214-D1219 . https://doi.org/10.1093/nar/gkv1031

68. BIOVIA Materials Studio 2019. DS Biovia

69. Mayo SL, Olafson BD, Goddard WA (1990) DREIDING: a generic force field for molecular simulations. J Phys Chem 94:8897-8909 . https://doi.org/10.1021/j100389a010

70. Horcajada P, Márquez-Alvarez C, Rámila A, Pérez-Pariente J, Vallet-Regí M (2006) Controlled release of Ibuprofen from dealuminated faujasites. Solid State Sci 8:1459-1465 . https://doi.org/10.1016/j.solidstatesciences.2006.07.016

71. Cerri G, Farina M, Brundu A, Daković A, Giunchedi P, Gavini E, Rassu G (2016) Natural zeolites for pharmaceutical formulations: Preparation and evaluation of a clinoptilolite-based material. Microporous Mesoporous Mater 223:58-67. https://doi.org/10.1016/j.micromeso.2015.10.034

72. Marchese Robinson RL, Geatches D, Morris C, Mackenzie R, Maloney AGP, Roberts KJ, Moldovan A, Chow E, Pencheva K, Vatvani DRM (2019) Evaluation of Force-Field Calculations of Lattice Energies on a Large Public Dataset, Assessment of Pharmaceutical Relevance, and Comparison to Density Functional Theory. J Chem Inf Model 59:4778-4792 . https://doi.org/10.1021/acs.jcim.9b00601 